\title{
Ostracism and Indirect Reciprocity: The Reproductive Significance of Humor
}

\author{
Richard D. Alexander \\ Museum of Zoology, Insect Division, \\ The University of Michigan
}

\begin{abstract}
Humor is hypothesized to be a social activity that alters the status of the humorist positively and that of the object or victim negatively. Of the two traditionally distingushed classes of humor, "ostracizing" humor singles out a victim, with others present or absent either incidental afifiliates of the humorist (and one another) or unaffected. "Affiliative" humor, on the other hand, is focused on creating or maintaining group cohesiveness, with the identity of the victim more or less incidental.
\end{abstract}

\section{INTRODUCTION}

Cynic

A misanthrope; spec., one who believes that human conduct is motivated wholly by self-interest.

\section{Webster's Collegiate Dictionary}

1947 Edition

A blackguard whose faulty vision sees things as they are, not as they ought to be...

\section{Ambrose Bierce's Devil's Dictionary}

1911 Edition

I

n developing a topic for my contribution to this issue, I selected humor because it is one of several attributes commonly seen as either antithetical or irrelevant to natural selection or reproductive success (music, art, aesthetics, humor ....), and committed myself explicitly to discussing it in terms of reproductive significance. I did this for two reasons: first, I thought it would be useful to extend my efforts toward topics likely to be most difficult to relate to evolution by natural selection; and second, in my course on human behavior and evolution, I had already developed a

Received September 14-16, 1984; revised March 19, 1986.

Address reprint requests to: Richard D. Alexander, Museum of Zoology, Insect Division, The University of Michigan, Ann Arbor, MI 48109. 
fairly detailed hypothesis about humor that related it to ostracism. Indeed, as will become clear, I unexpectedly found the analysis converging on conclusions I had reached earlier with respect to morality (Alexander 1982, 1985, in press).

For the purposes of my discussion, I define ostracism from my 1947 edition of Webster's Collegiate Dictionary as "A method of temporary banishment by popular vote . . Exclusion by general consent from common privileges, favor, etc. [read: resources of reproduction] . . . as, social ostracism."

Ostracism is a topic of almost unbelievably broad significance. I see it as varying from such extremes as shunning, excommunication, and designation of "outlaw" to the most subtle forms of status shifting through implied or real, partial or complete exclusion from temporary or even momentary and casual groupings of social interactants. I see ostracism as an instrument for the manipulation of conflicts and confluences of interest through adjusting access to resources. Conflicts and confluences of interest, I believe, underlie everything that is social about humans. What sets us apart from other organisms more than anything else seems to be (1) the astonishing complexity of our conflicts and confluences of interest (deriving from the fact that we continue our lives together as large groups of long-lived adults and children mixed as relatives of varying degrees-also the reason for the prominence and elaborateness of incest avoidance-and as accomplished social cooperators, reciprocators, and competitors with countless ways of helping and hurting one another); and (2) the extraordinary array of proximate mechanisms we have evolved for assessing and dealing with our conflicts and confluences of interest. Underlying it all, I believe (cf. Alexander 1979), is the fact that humans achieved, apparently a very long time ago, a peculiar situation in which the greatest threats (and aids) to individuals and groups come from other humans rather than other species. The nature and complexity of the human psyche, I believe further, with its aspects designated as conscious, preconscious, subconscious, and nonconscious-as conscience, intelligence, self-awareness, foresight, and all the rest-relate powerfully to the problems of dealing appropriately with conflicts and confluences of interest within the human social scene. Thus I see consciousness, self-awareness, foresight, and conscience as "overrides" of more ancient and more immediate indicators of costs and benefits (such as pain and pleasure). Humans use consciousness, self-awareness, foresight, and conscience to estimate long-term costs and benefits and to make decisions about rejecting short-term pleasures or accepting short-term pains. The special condition favoring such attributes, I hypothesize, is the ability of competing and cooperating humans to adjust continually the relationships between shortand long-term costs and benefits so that intelligence, foresight, and deliberate planning have been the best available tools for realizing one's own interests (for fuller discussion, see Alexander 1979, and in press).

I have used the term "indirect reciprocity" in my title, and this also 
deserves some explanation (see Alexander 1977, 1979, 1985, in press; also see Trivers 1971, under the term "generalized reciprocity"-but not generalized reciprocity as used by Sahlins 1965).

Direct reciprocity occurs when an individual (or a group) is beneficent toward another and is repaid for his temporary altruism (or social investment) by a parallel act of beneficence, not necessarily involving the same currency, but typically resulting in gains for both interactants (Trivers 1971, defined this condition formally and referred to it as "reciprocal altruism").

Indirect reciprocity occurs when interested people observe direct reciprocity between others and use the observations to determine who will be their own future associates and how they will interact subsequently with the observed parties. Indirect reciprocity occurs whenever rewards or punishments come from individuals or groups other than those directly involved in a social interaction involving investment or exploitation. It includes public and private opinions, and status. Indirect reciprocity is the foundation of moral, ethical, and legal systems. Its existence and pervasiveness in human social life, I believe, are the most important factors to consider in an analysis of the nature and complexity of the human psyche. I think they account for human interest in theater in all of its guises, from soap operas to Shakespeare, poetry to sociology, neighborhood parties to the Olympic games. Indirect reciprocity is the reason that very few things are more relevant to our individual social success than the ability to see ourselves as others see us and respond appropriately (which means, I think, to cause them to see us as we wish them to, and not otherwise).

In this article I consider the hypothesis that humor is a principle according to which the evolved abilities and tendencies of people to see themselves as others see them, to use ostracism to their own advantage, are manipulated so as to induce status shifts-both subtle and not so subtle. My general hypothesis is that humor has developed as a form of ostracism and that, historically, at least, ostracism has tended to affect the reproduction of the ostracized individual (or group) deleteriously, especially in relation to the reproduction of the ostracizers, by restricting access to significant resources.

To my knowledge there is no well-developed previous theory of the function of humor, in the sense of evolved or "ultimate" function, even though the literature on humor is filled with hints in the direction I take this article. [Thus, Robinson (1977) says that "studies . . . describe the function of humor to solidify the in-group, to attain gratification at the expense of another group . . ." and "There is a pecking order to joke-telling. The joketeller is the dominant one; the joke is his weapon; his laughter is a sign of victory. The audience is submissive; their laughter is the sign of their acceptance of defeat."] Absence of explicit theories of function seems to result partly because previous authors have either attributed "function" solely or in part to the satisfaction of some proximate system or mechanism, or because they have avoided the question of ultimate (usually given as "sur- 
vival"') function, sometimes giving the reason that the question is not experimentally testable (for reviews, see McGhee 1979; Schmidt and Williams 1971).

To say that a particular behavior or tendency exists or is carried out to satisfy pleasure, relieve frustration, or even to help one deal with an immediate situation in the sense of adjusting one's frame of mind (e.g., gallows humor, as exemplified by Freud's description of the man who, on his way to the gallows on a Monday, steps out into the sunshine and remarks, "Well, the week is beginning nicely.") begs the question of the reason for the existence of the effect (pleasure, relief, comfort) or the recognition of a mental "problem" (frustration, wrong frame of mind). Pleasure and pain presumably exist because, respectively, they cause us to repeat beneficial actions and avoid repeating deleterious ones (Dawkins 1976; Alexander 1979). Similarly, frustration exists, I would speculate, because of the importance of solving problems that may be difficult. The question we have to deal with eventually, and on which I concentrate here, is precisely what such immediate mechanisms are programmed to accomplish-that is, how are actions determined to be "beneficial" and "deleterious"?

Typically we suffer pain when we incur an injury that, prior to medical technology, was reparable provided certain actions were taken and others avoided (as in protecting an injured part). We typically do not suffer pain when injuries irreparable prior to medical technology occur (e.g., object thrust into the brain, damage to the spinal cord). I assume that mental pain and pleasure analogues serve similar functions in the social scene-e.g., that the only way, in the end, to deal with frustration and distress is to solve the problem that is causing it. In other words, I see frustration and distress as mechanisms serving some function, not as either incidental or pathological conditions to be relieved per se, without connection to other difficulties. Thus, I do not use the word "function" as Flugel (1954) used it when he said that "it seems clear that one important function of the humorous attitude at all levels is to relieve us from the burden of reality . . " (p. 713). I will argue, in the end, that the kind of humor or the aspects of humor that in Flugel's sense make us feel good (e.g., humor among patients in a cancer ward) stem from group-unifying aspects of humor that originally gave us pleasure because they cause groups to be more effective competitive units in intergroup competition (hence, as in the cancer ward, seem to reduce some other hostile force by providing additional motivation to deflect it).

I do not wish to underestimate the complexity of relationships between proximate and ultimate aspects of humor and its correlates, such as changes in facial expression and laughter. Zajonc (1985) gives reasons for believing from physiological effects that "laughing must be healthy . . ." and Roger Masters (personal communication) has similarly reminded me of the saying that "laughter is the best medicine," adding: "Laughter, as a predictable consequence of humor, has a physiological effect on the organism [see also Cousins 1979]. We know that agonic emotional states inhibit learning . . . 
and . . fear is generally associated with both subordinate status and ineffectual coping with environmental novelty. It follows that hedonic states of emotion have, in the absence of life-threatening situations, a likelihood of improving reproductive success. If so, laughter could . . . be positively reinforcing because it is associated with the effective coping behavior."

The question one has to consider is why laughter should be healthy or have beneficial effects on our physiology or behavior? If, as Zajonc and Masters suggest, the reason is purely physiological-say, through effects on blood flow to or from the brain-then one has to ask why we do not laugh all the time or modify the involved physiological conditions so that we experience the beneficial effects without having to laugh. The alternative is that beneficial effects of laughter or humor, measured as physiological, are only beneficial in social situations that evoke laughter. That is, laughter is caused by social situations that in turn cause the laughing individual correctly to have a kind of confidence that allows concentration on things like learning or coping with novelty or whatever social effects accrue from hedonic feelings. In other words, whatever the original physiological causes or effects of laughter, its social effects must have led to feedbacks that altered the physiological effects and associated behaviors appropriately (moreover, once humor and laughter had come to have beneficial physiological effects, new vistas would be opened for the "entertainer" who could raise his own status by creating both the social and the physiological effects in situations in which they would otherwise not occur). This view lays great emphasis on the social effects of humor and laughter, and I am convinced that this emphasis is proper. It does not alter significantly the search for ultimate function, which is important because it is also the ultimate shaper of the trait.

\section{HUMOR AND STATUS}

\section{General Hypotheses}

Note: I have tried to make the following set of interrelated hypotheses internally consistent, meaning that each subhypothesis, if true, should support the main hypothesis and, if false, deny it. I have also tried to make this set of hypotheses exhaustive-that is, I have tried to include every situation I can think of that involves humor. In addition I have attempted to use Darwin's (1859) two methods of (1) describing phenomena that, if observed, would deny my hypothesis; and (2) analyzing observed phenomena that seem difficult to explain by my hypothesis. The reader will see that I have not accomplished all of these goals, but perhaps my efforts will help others who analyze humor to achieve them later. 


\section{Status Effects}

I use status according to the definitions "position of affairs" or "state or condition of a person" (Webster's Collegiate Dictionary, 1947 ed.). My hypotheses assume that the following are desirable (sought-after) effects on status, meaning as well that I assume that these effects typically influence reproduction favorably by improving access to resources:

1. Elevating of one's own status in relation to
a. Part of the group (audience)
b. All of the group (audience)
c. One or more third parties not present

2. Lowering of someone else's (the "victim's") status in relation to one's self
a. The victim is the only individual present.
b. The victim is not the only one present.
c. The victim is not present.

3. Reinforcing (maintaining) a presumably favorable status relationship with
a. Part of the group (audience)
b. All of the group (audience)
c. One or more third parties not present

The basic hypotheses, then, from which all those that follow are derived, are as follows:

1. Jokes involve tricks. Trick is defined as "An artifice or strategem; crafty procedure or practice; a cheating device" (Webster's Collegiate Dictionary, 1947 ed.). In my opinion, dictionary definitions of cheating are unsatisfactory, so I define cheating here as breaking rules or manipulating them in an unacceptable fashion; I define rules as established procedures or contracts.

II. Tricks are devices for lowering status of those on whom they are played and raising the status of those who play them. Telling jokes, and laughing at them, are ways of adjusting status in one's own favor.

III. Based on the hypothesis of ostracism or status-shifting, humor seems to develop as two related forms:

A. Jokes that explicitly exclude or lower the status of a party or parties (by representing a trick played successfully upon the demoted party) and thereby also indirectly or seemingly incidentally (implicitly) bond together those who are party to the joke (trick) or share it (e.g., ethnic, racist, or sexist jokes).

B. Jokes that implicitly exclude or lower the status of some individual or recognizable group by explicitly reinforcing fellowship or cohesiveness or unity in the group (among the individuals) sharing the joke. These include the kinds of jokes that influenced Stephen Leacock to write that "Humor may be defined as the kindly contemplation of the incongruities of life, and the artistic expression thereof." (See also the dictionary definition as "that quality which appeals to a sense of the ludicrous or absurdly incongruous.") 
Leacock (1938) wrote in a way that anticipates (but obviously does not correspond precisely to) the dichotomy in humor proposed here:

One is tempted to think that perhaps the original source [of humor] parted into two streams. In one direction flowed, clear and undefiled, the humor of human kindliness. In the other, the polluted waters of mockery and sarcasm, the "humor" that turned to the cruel sports of rough ages, the infliction of pain as a perverted source of pleasure, and even the rough horseplay, the practical jokes, and the impish malice of the schoolboy. Here belongs "sarcasm" - that scrapes the flesh of human feelings with a hoethe sardonic laugh . . . the sneer of the scoffer, and the snarl of the literary critic as opposed to the kindly tolerance of the humorist.

Similarly, O'Connell (1960) stated that, following Freud, "humor" and "wit" separate into approximately the two general kinds of humor I have postulated here, humor being associated with empathy and wit with hostility. Robinson (1977) wrote that "Studies . . . describe the function of humor to solidify the in-group, to attain gratification at the expense of another group, and, more recently, as a way to create a new image and as an agent of social change. The role of the fool in society has been described as a means of enforcing group norms of propriety."

Robinson also noted, tellingly, that in the medical community "the critical issue is that it is never justifiable to make fun of or laugh at the patient or his symptoms. Laughing with someone rarely does harm" (Robinson 1977, p. 79.)

Freud (see Brill 1938), Eysenck (1947), and Flugel (1954) looked for three levels or kinds of humor, variously termed conative (wit), affective (humor), and cognitive (comic). I cannot distinguish the second and third (see also below).

$I V$. Humor is associated with smiling and laughing. Smiling (visual) and laughing (auditory and visual) are ways of communicating pleasure (truthfully or deceptively). The pleasure of smiling and laughter is a social phenomenon.

Laughing probably occurred first as a result of physical events like tickling, which also has social significance, and which occurs in chimpanzees (at least) as well as in humans (Darwin 1899; Yerkes and Learned 1925; Goodall 1968). Goodall (1968, p. 258) stated that "' 'Laughing' (a series of staccato panting grunts) frequently accompanied bouts of wrestling and tickling." Goodall also noted that, in "greeting behavior . . . as two individuals approach each other they may utter soft or loud panting sounds . . particularly the subordinate as it bows, crouches, or bobs. Sometimes both the dominant and the subordinate individuals may "grin." [See McGhee (1979) for numerous examples from primates.] Today laughter among humans probably occurs most frequently during social communication without physical contact.

It is worth stressing that what we are required to explain is not only why what we call humor causes pleasure but (especially) why special mech- 
anisms exist for the communication of the pleasure that derives from humor (eventually, the same problem must be taken up with respect to grief and crying). In the case of tickling, it seems a reasonable hypothesis that vocal and other physical responses originally functioned (i.e., had as their evolved significance) to keep the tickler tickling. Two curious aspects are that (1) we cannot successfully tickle ourselves [Flugel (1954) remarked on this fact] and (2) our tendency to be ticklish renders us vulnerable to a kind of cruelty in the form of unwanted tickling. I see this vulnerability as paralleling the vulnerability of humans who have evolved to appreciate and use humor that does not involve physical events like tickling to having this appreciation and sensitivity as well turned against them. Vulnerability to excessive tickling, or excessive responsiveness to tickling, sometimes takes the form of being "goosey," meaning to be so intolerant of tickling-or even the threat of tickling - that a word, gesture, body movement, or simply a stare can be a form of torture and can cause a susceptible individual to do extraordinary things like leap out of a window or injure himself in a frantic effort to escape, even when the tormentor is some distance away.

\section{Evolutionary Origins of Smiling and Laughter}

Smiling and laughter have been postulated either to represent a "continuum of graded intensities" (Andrew 1963; Hinde 1974) or to have different phyletic origins (Van Hoof 1967, 1971; Lockard et al. 1977). Following the first alternative, Darwin (1899) seemed to postulate that laughing preceded smiling, and Hayworth (1928) agreed. Van Hoof (1971) and Lockard et al. (1977) suggested that smiling evolved from the "silent bared-teeth submissive grimace . . . of primates, and laughing . . from the relaxed open-mouth display ... of play." Both displays are known in several primates (Macaca, Cercopithecus, Pan, Mandrillus, and Theropithecus). Although I am inclined to agree with Darwin and Hayworth, the two alternatives may not affect significantly the arguments presented here.

\section{Ontogeny of the Sense of Humor}

Presumably, the evolution of smiling and laughing in infants, as with many other aspects of infant social behavior, followed the evolution of functions in smiling among adults. In this hypothesis the infant would be enhancing its attractiveness to those responsible for its future by mimicking social responses that in adults signify good will and comaraderie. The alternative hypothesis would be that smiling originated as a part of the attractiveness of infants and acquired its social significance among adults (acknowledgement of subordinance?) later, and perhaps as a result of its significance in the parent-offspring interaction. In a sense both hypotheses may be correct in this case. Thus, smiling may have evolved out of a grimace associated with being tickled, and tickling may have evolved out of physical interactions 
between parent and offspring. As smiling acquired more profound implications in the complex social world of adults, there may have been significant feedback enhancing smiling and laughing in infants.

McGhee (1971) says "Grotjahn (1957) argued that the child first discovers comic situations when he begins to master and enjoy body movements. When he begins to feel superior to other children in this respect, he is likely to see their mistakes or weakness as funny." McGhee (1971) reported that "While speech mistakes and other bumbling errors (e.g., slipping on a banana peel) are funny in their own right to the healthy child, they may become the source of cruel and derisive laughter in the child who feels unloved or unsure of himself." Leuba (1941) noted that if a playful attack (e.g., of tickling) becomes too serious, laughter in younger children turns into expressions of fear. Wolff et al. (1934) similarly stated that "A child, for instance, who has made a remark which because of its naive cleverness evokes laughter may burst into tears if the mirth is too openly expressed." Jones (1926) stated that the same stimuli might arouse laughter in 16-36month-old children on one occasion but crying in another. Justin (1932) found that only incongruity "was found to increase in its effectiveness in producing laughter as a function of age" (among surprise or deflated expectation, superiority and degradation, incongruity and contrast, social smile as a stimulus, relief from strain and play situations; these did not change during ages $3,4,5,6)$. This last finding suggests that the directly integrating aspect of humor, aside from the infant's smile, appears later in development than the directly ostracizing aspect. The other findings indicate that children have more difficulty than adults separating the two kinds or effects of humor.

Robinson (1977) says of "mature humor" that it "signifies . . emotional maturity and . . . is based upon deeper life experiences and kindly, tolerant acceptance of oneself and therefore of others."

These remarks seem to me to integrate interestingly with Flugel's 1954 note that McDougall (1923) "draws attention to the aesthetically interesting fact that smiling is beautiful, whereas laughter is ugly. Both smiling and laughter appear in human infants at an early age, and all observers seem to agree that developmentally the smile precedes the laugh." If smiling associates with the "mature" humor of integration and laughter with the explicitly ostracizing function of humor, then the hypothesis is supported that smiling by infants without physical contact may indeed have evolved after the integrative function of humor was established. A test would be whether or not infants of nonhuman primates smile without physical contact. The alternative is that laughter evolved after smiling, and the ostracizing function of humor after the integrating function. This argument is supported by Laing's (1939) finding that the unusual "arouses laughter earlier than the discomfiture of others, and that both precede anything which might be called ' $w i t$,' which in turn is, in its early stages, visual rather than verbal" (Flugel 1954, p. 712). Laing supposedly found that the developmental order could be described as "absurdity," "slapstick," "satire," or "whimsey." But none of 
these words-except possibly the first-seems to describe the integrative aspect of humor, or that associated with smiles as opposed to laughter.

\section{Sex Differences in Humor}

The only sex differences I have found so far seem to support the general hypothesis of ostracism. Thus, O'Connell (1960) found that men appreciate "hostile wit" more than women do, while women prefer "nonsense humor." Jones (1926) found that girls smile more while boys laugh more. Laing (1939) found that "girls more often deprecated "unfeeling laughter." 'It has also been argued that males tell jokes more often than females, and that they tell more sexual jokes (for the latter, see Flugel 1954). These meager findings are consistent with the prevailing opinion that men compete more intensely than women and that they tend to do so more frequently in coalitions (cf. Alexander 1979; Symons 1979).

\section{Hypothesized Stages in the Evolution of Humor}

Stage 1. It becomes useful to scratch or groom oneself to remove parasites or for other reasons.

Stage 2. In social organisms-such as between parents and offspring, mates, or siblings (probably in all extensively parental species)-it becomes useful (because of kin selection) to groom relatives or mates (initially for the same reasons as above).

Stage 3. Grooming and similar activities acquire social significance beyond removal of parasites and other original functions. They represent or suggest a willingness to invest in the groomed individual. Thereby they also signify a kind of exclusivity; the implication that there is a greater or an exclusive willingness to invest in the groomed individual rather than in other individuals. This public willingness already implies ostracism by defining a group with a certain relationship that includes the groomer and the groomee-the tickler and the ticklee. If all individuals were equally willing to invest in all other individuals this implication would not arise. If it were not important for a relationship to be exclusive, I am saying, all grooming would not take the forms it does. The suggestion of exclusivity may have had its initial significance for the groomee only, but in group-living species with complex shifts of interests, where other individuals could observe grooming, it would very quickly acquire significance for observers as well as participants. I suggest that the intimacy and exclusiveness of tickling and grooming interactions are why they usually cause uneasiness in some observers (necessarily being excluded), especially when they become intense or are long continued. [elsewhere-Alexander (in press) - I argue that because of indirect reciprocity public aspects of nepotistic and reciprocal interactions are crucial in understanding their overall significance.] Radcliffe-Brown's (1965) dis- 
cussion of the "joking relationship," which appears to have ritualized significance between particular kinds of relatives in certain societies, is relevant here.

Stage 4. Special responses to grooming begin to evolve (This effect probably started earlier, but the aspects of most concern to us here would likely become complex and significant as Stage 3, above, developed.) These aspects could include appreciative stances, movements, or vocalizations. As such responses evolve, there will be tendencies to try to elicit them. Tickling and its associated laughter, squirming, and focusing by the tickler on the ticklish spots make up one example. At this stage both grooming (and its relatives such as tickling) and responses to grooming may begin to acquire social significance beyond either (a) the willingness of the groomer to invest and the groomee to accept the commitments and (b) the observation by others of the mutual commitment. That is, the grooming (tickling, horseplay, necking, petting, whatever) may become a game (or a deception) in which the principal significance for one or both interactants is not to develop a deep or long-lasting commitment to the other but to attract the attention of observers who may be better partners in such investments. Similarly, such interactions (as in preadults) may be primarily practice or learning experiences useful in later repetitions.

It has been suggested that tickling typically involves stimulation of body areas that would be vulnerable in combat. This suggestion is consistent with the notions that (1) tickling is play (and play is practice), (2) tickling and laughter are parts of interactions involving trusted associates, and (3) tickling and laughter reassure (e.g., Hayworth, 1928). In effect, "affiliative" humor may be derived from play, or take its form from play. (I do not think this possible interpretation changes my arguments, but it requires more development than I can give it here.)

Stage 5. Laughter and expressions of pleasure become liberated from the context of physical grooming, tickling, etc.- -and also from such contexts as courtship-and begin to be expressed in other social situations. This step can only be taken as social reciprocity becomes important as the binding cement of sociality. That step, in turn, depends upon the organism living in social groups composed at least of a complex mix of relatives of varying degree and different and fluctuating reproductive potentials (hence, not uniformly sharing interests or requiring assistance) and probably as well including sets of nonrelatives. [See Alexander (in prep.) for a fuller justification.] As earlier arguments have emphasized, there are always special reasons for such group-living, and because group-living entails automatic expenses that must be compensated before it can evolve, these take the form of one or another kind of hostile force (Alexander 1974, 1979). In humans, probably from the earliest times, these hostile forces are likely to have included other human groups. This fifth stage may be said to represent the appearance of humor in its modern form. 


\section{Is Humor Ever Nonostracizing?}

As related above, humor is seen here as a status-altering or ostracizing form of activity. One is tempted to ask whether, as in Leacock's view, a sixth stage has been achieved in which some humor has acquired a social significance that rises loftily above the two categories here described (III A,B), both of which seem to come off as a bit grimy and contemptible. Flugel (1954) raises essentially the same question but does not resolve it (see also Freud, in Brill 1938; and Eysenck 1947). In the arguments presented here the question becomes whether or not "affiliative" actions (humor) have as their ultimate function the competitive success of the thereby unified cooperative group as compared to other groups (or individuals). In evolutionary terms I believe the argument can be sustained that cooperative group-living can only evolve by increasing the reproductive success of the group members as compared to those living alone or in other groups. The reasons are that (1) reproductive success is relative and (2) cooperative group-living cannot be maintained and elaborated unless all of the participants somehow improve their reproductive success. If all group members accomplish this, then the relevant comparison can only be between members of different groups (see also Alexander 1979, in press). This means that group cooperativeness always implies at least indirect intergroup competitiveness; humans, at least, have obviously not left intergroup interactions in this realm but placed them at center stage by making them direct, elaborate, and continual.

Interestingly enough, especially considering another humorist's high opinion of humorists (Leacock, quoted earlier), Ambrose Bierce (1911) defines one word in his Devil's Dictionary in a way that is neither cynical nor humorous. The word is "humorist," which he defines as "A plague that would have softened down the hoar austerity of Pharoah's heart and persuaded him to dismiss Israel with his best wishes, cat-quick." As a contrast, especially for the purpose of this essay, the word just before "humorist," which is "humanity," he defines as "The human race, collectively, exclusive of the anthropoid poets." (Bierce undoubtedly saw himself as a humorist, as did Leacock. Even cynical humorists, evidently, do not typically enjoy jokes on themselves.)

It is most paradoxical, at first, to imagine that which seems to bring us considerable social reward and pure pleasure as unpraiseworthy. But we already know that the paradox exists. All of us have at one time or another been filled with mirth at an episode or story that we would not share completely and that we knew mortified or denigrated some other, and would do more severely (too severely?) if it were known to all. What I am hypothesizing here is that in some sense this is true of every aspect of humor, and that not only human social structure in general but the human psyche as well has evolved in a milieu in which subtle and complex forms of ostracism were inevitably a principal ingredient. Elsewhere (Alexander, in press), I argue similarly that morality and justice are concepts founded on the idea, 
not of equality for all, but of ostracism and exclusivity; they represent either gestures or convictions with respect to some kind of equality within a group, but explicitly not beyond it and in fact for the purpose of excluding some others. The problem in our modern, dangerous world seems to be in diminishing the one tendency while retaining and expanding the other; Darwin (1871) recognized and described this problem in almost the same terms as modern writers (e.g., Singer 1981).

I emphasize that the argument that humor is invariably either direct or indirect ostracism (as opposed to being solely ostracizing in one situation and solely integrating in the other) stands or falls on the assumptions that (1) cooperative groups form as defenses against hostile forces and (2) human groups have for a very long time had as their raison d'etre the existence of other competitive and hostile groups (for references and a development of the argument, see Alexander 1979; Strate 1982).

This is not to suggest that what would typically be seen as a cynical view means that there is no escape-no way to alter any inelegant or paincausing activities or attitudes of humanity. But I do mean to imply that recognizing such, when and if they exist, has a certain likelihood of assisting in efforts toward social harmony on grander and more nearly universal scales, perhaps through explicit and deliberate promotion of effects of humor that integrate and diminution of effects that ostracize.

The joking relationship is a . . relation between two persons in which one is by custom permitted, and, in some instances required, to tease or make fun of the other, who in turn is required to take no offense.

(Radcliffe-Brown 1965, p. 90)

Greenland Eskimos ... resolve their quarrels by duels of laughter. The one who gets the most laughs from the audience wins. The other, humiliated, often goes into exile.

(Robinson 1977, p. 103)

Sudden glory is the passion which maketh those grimaces called laughter.

(Thomas Hobbes 1651, p. 57)

\section{Kinds of Jokes}

What follows is an effort to see if different kinds of jokes in different situations seem to support or deny ideas expressed earlier. It is not a particularly good effort at falsification, but it may point the way to better ones.

A. Puns and shaggy dog stories are regarded as the "worst" or "lowest" forms of humor because the trick is on the listener.

1. Puns are "worst" when told to a single person, who is obligatorily the object of ridicule. This does not mean that the greatest status shift will take place when a pun is told to a single individual but that it is difficult for either individual to gain when a pun is told to a single individual. Jokes told to single individuals typically are the kind that lower the status of a third party not present. 
2. Puns are "best" (i.e., most liked by listeners) when told to several listening parties. The reason is that the others can laugh at the one to whom the joke seems directed (which means as well that the joke can serve the "integrating" or "unifying" function). This hypothesis seems to assume that jokes involving tricks on listeners will be directed at one member when the audience includes several individuals, and usually not to the one with the highest prestige or the one least vulnerable to a downward status shift. The exception to the second part of the exclusion is when the joke-teller has very high status and is explicitly trying to lower the status of the individual currently holding the highest status in the group.

B. The "best" jokes are those that seem to elevate the status of the listener (e.g., in relation to some third party, by putting that party down). For example, James Herriott, in a series of humorous books about his life as a veterinarian in Scotland (e.g., Herriott 1972), has the ability to cause the episodes of his life to appear as a series of jokes upon himself, in which "tricks" on the other participants typically seem known only to the readers of Herriott's books (i.e., the "trick" is that the others are being "observed" in their idiosyncrasies by both Herriott and his readers). The effect is to give an impression of raising the status of the readers, and I speculate that this is one cause for the enormous success of Herriott's books. On the other hand, Ben K. Green, in a series of books about his life as a veterinarian in West Texas (e.g., Green 1971) typically portrays himself as the clever winner of every set-to, with the other parties getting their just due and knowing it. Even if the individual stories are inherently funny and well-told, the overall effect on the reader is quite different, an uneasy feeling appears, and the reader tends not to like Ben K. Green nearly as well as he does James Herriott, who has generated truly memorable feelings of affection among his readers. (Perhaps, as one reader suggests, the reason for Green's failure is that he is not as effective as, say, Mark Twain at his cynical "againstthe-world" best at causing the reader to identify with him.)

\section{Telling jokes on others is a way of:}

1. elevating one's own status;

2. lowering the status of the butt of the joke;

3. elevating the status of the listener by:

a. allowing him to be in the right situation to laugh;

b. lowering the status of the object of ridicule;

4. increasing camaraderie or unity by identifying the butt of the joke as a member of an adversary group or a common object of ridicule.

D. Telling jokes on oneself is a way of:

1. trying to elevate the status of the listener so as to set up a better relationship between one's self and the listener; 
2. trying to show that one's own status is so high that it can be lowered without changing the basic nature of the relationships;

3. trying to channel an already existing joke on one's self so that its effect on one's status is less than would otherwise be the case.

E. Laughing at jokes on oneself is a way of:

1. counteracting the effect of the trick, showing that it causes pleasure, therefore could not be detrimental-i.e., turning the trick back on the joke-teller (Rodney Dangerfield does not lower his status by describing the endless ways in which he purportedly has failed to get respect; that he does not, while pretending to, is, of course, his best joke);

2. accepting the implicit status shift in the interests of a better future relationship with the joke-teller or listeners (or both).

F. Laughing at jokes in the presence of others is a way of saving status in the situation through:

1. showing (claiming) that you recognize the trick and would never be so naive as to be taken in the same fashion;

2. telling the joke-teller (and other listeners) that you and he (they) are on the same side and see others (the objects of ridicule) the same way;

3. elevating (or assuring) the joke-teller's status in relation to you or some others (A joke can be given as a gift to a friend-i.e., as an item to be used by the recipient to his own advantage. In my experience such transfers are frequently followed by the receiver of the "gift" relating to the donor how effectively it worked.)

G. Jokes on sacred topics are a way of showing that:

1. one is extremely sophisticated (has high status) and can afford to be unconcerned about the sacredness of the topic;

2. the sacred topic is not so important (to anyone).

H. Failing to laugh at someone else's jokes is a way of:

1. putting down the story-teller;

2. showing one's own sophistication, dominance, or independence.

I. Laughing "too" hard suggests a very strong ("too" strong) effort to realize the above functions, hence implies a feeling of low status and special need to elevate one's own status.

J. The ultimate putdown is to see humor in a situation, or in a joking effort, when it is not seen by the person being put down. That person has two choices:

1. he can laugh and pretend he "got the joke"; or

2. he can sniff and pretend that he understood the joke but did not regard it as funny. 
(Note: The above situations do not exclude circumstances in which a purveyor of humor elevates the status of an object of his humor in relation to others in a group, but it does seem to preclude raising of the status of an object of his humor in relation to the humorist's status unless the status of the others is so lowered as to result in a net elevation of the humorist's status. In cases that may seem to the observer to have nothing to do with status shifts it is usually revealing to visualize a reversal of the identities of the teller of the joke and its object.)

Obviously if the situation is such that the status of the listener is not being threatened in respect to the joke-teller and many others in the group, but instead the general nature of the joke promises to elevate the listener's status-in relation to say, some third party or class of people-then the listener may accept the tiny loss of status from admitting that he did not "get" the joke and reap the rewards of being able to laugh along with everyone else at the object of ridicule.

\section{DISCUSSION}

None of the above is an argument that laughter cannot be truly pleasurable, that humor is never sincerely funny, or that any of the above functions or outcomes are in the conscious minds or motivations of people who tell or respond to jokes. To contrast or oppose such proximate results of humor to its possible reproductive significance is to muddle the relationship between functions and the mechanisms which bring them about. It also overlooks the potential significance of self-deception in a world in which deliberateness in deception of others is the worst of all social transgressions, and sincerity (even what the psychologist Donald T. Campbell calls "sincere hypocrisy") is viewed as a noble virtue. The question is whether or not the above outline of hypotheses tends to clarify cases of "sincerely funny" humor as well as the kinds that some of us believe we already see as pernicious or as serving those who actively perpetuate them and sympathetically respond to them.

This raises another issue, emphasized by the fact that people chuckle to themselves when alone, and also seek out cartoons and other humor to read and enjoy in solitary, even if they do not intend to (and do not) mention these experiences to others. Depending on the precise circumstances and consequences, this fact may not be negative to the hypotheses discussed here. The reason is that social success may be powerfully enhanced by adjusting one's outcomes as a result of social scenario-building. There is no reason to believe that humor is exempt, and the degree to which it actually does contribute to status shifts should reflect the degree to which it has become involved in the scenario-building. In other words, if understanding and responding to jokes is an important kind of social behavior, then a little practice may be useful. I would hypothesize, then, that when laughter and 
humor are expressed by solitary individuals (and even when they seem to the individual to be completely internal and personal), they are secondary derivatives of social situations, representing scenario-building that will have its effect in later social situations, including the indirect and anticipated communication of the writer or performer for an absent reader, viewer, or interactant.

I end this speculative essay on the note that whether or not the particular arguments presented here are correct in any significant way, they may support the notion that it is appropriate to examine topics like humor in the context of evolved biological (reproductive) function, and that humor-as an aspect of ostracism, and of coalition formation and maintenance-is a topic worth careful scrutiny as we intensify our concern with the problem of peaceful coexistence in an ever-more dangerous world of technological sophistication and balance-of-power races.

God works wonders when he can

Here lies a lawyer, an honest man

Gracious! The two of them buried in the same grave!

Modified from Aye (1931)

For criticisms and assistance I am grateful to the other participants in this project and to the members of the Human Behavior and Evolution Group at the University of Michigan. I particularly thank Bobbi S. Low, Laura Betzig, Paul Turke, Beverly Strassmann, and Roger Masters.

\section{REFERENCES}

Alexander, R.D. The evolution of social behavior. Annual Review of Ecological Systems 5: 325-383, 1974.

- Natural selection and the analysis of human sociality. In Changing Scenes in the Natural Sciences, 1776-1976, C.E. Goulden (Ed.). Philadelphia: Bicentennial Symposium Monograph, Philadelphia Academy of Natural Science, Special Publication (12), 1977, pp. 282-337.

Darwinism and Human Affairs. Seattle: University of Washington Press, 1979.

Biology and the moral paradoxes. In Law, Biology, and Culture: The Evolution of Law, M. Gruter and P. Bohannon (Eds.). Santa Barbara, CA: Ross-Erikson, 1982, pp. 101110. (Also Journal of Social and Biological Structures 5: 389-395, 1982.)

- A biological interpretation of moral systems. Zygon 20: 3-20, 1985.

- The Biology of Moral Systems. Hawthorne, New York: Aldine Press.

Andrew, R.J. Evolution of facial expression. Science 142: 1034-1041, 1963.

Aye, J. Humour among the Lawyers. London: The Universal Press, 1931.

Bierce, A. The Devil's Dictionary. New York: Thomas Y. Crowell, 1911.

Brill, A.A. The Basic Writings of Sigmund Freud. New York: The Modern Library, 1938.

Cousins, N. Anatomy of an Illness, New York: Norton, 1979.

Darwin, C.R. 1859. On the Origin of Species. A facsimile of the first edition with an introduction by Ernest Mayr, published in 1967. Cambridge, MA: Harvard University Press.

Darwin, C.R. The Descent of Man and Selection in Relation to Sex. New York: Appleton, 1871,2 vols.

- The Expression of the Emotions in Man and Animals. New York: Appleton, 1899. 
Dawkins, R. The Selfish Gene. New York: Oxford University Press, 1976.

Eysenck, H.J. Dimensions of Personality. London: Kegan Paul, 1947.

Flugel, J.C. Humor and laughter. In Handbook of Social Psychology Cambridge, MA: AddisonWesley, 1954, Vol. 2, pp. 709-734.

Goodall, J. The behavior of free-living chimpanzees in the Gombe Stream Reserve. Animal Behavior Monographs 1: 165-311, 1968.

Green, B.K. The Village Horse Doctor West of the Pecos. New York: Knopf, 1971.

Grotjahn, M. Beyond Laughter. New York: Macmillan, 1957.

Hayworth, D. The social origin and function of laughter. Psychological Review 35: 367-384, 1928.

Herriott, J. All Creatures Great and Samll. New York: Bantam, 1972.

Hinde, R.A. The Biological Bases of Human Social Behavior. New York: McGraw-Hill, 1974.

Hobbes, T. Leviathan; or the Matter, Form and Power of a Commonwealth. Indianapolis: Bobbs-Merrill, 1958 (original publication 1651).

Humphrey, N.K. The social function of intellect. In Growing Points in Ethology, P.P.G. Bateson and R.A. Hinde (Eds.). Cambridge: Cambridge University Press, 1976, pp. 303321.

Jones, M.C. The development of early behavior patterns in young children. Pedagological Seminary 33: 537-585, 1926.

Justin, F. A genetic study of laughter provoking stimuli. Child Development 3: 114-136, 1932.

Laing, A. The sense of humour in childhood and adolescence. British Journal of Educational Psychology 9: 201, 1939 (abst).

Leacock, S. Humor and Humanity. An Introduction to the Study of Humor. New York: Henry Holt, 1938.

Leuba, C. Tickling and laughter. Journal Genetic Psych 58: 201-209, 1941.

Lockard, J.S., Fahręubruch, C.E., Smith, J.L., Morgan, C.J. Smiling and laughter: Different phyletic origins? Bulletin of the Psychonomic Society 10: 183-186, 1977.

McDougall, W. An Outline of Psychology. London: Methuen, 1923.

McGhee, P.E. Development of the humor response: A review of the literature. Psychological Bulletin 76: 328-348, 1971.

Humor, Its Origin and Development. San Francisco: Freeman, 1979.

O'Connell, W.E. The adaptive functions of wit and humor. Journal of Abnormal Social Psychology 61: 263-270, 1960 .

Radcliffe-Brown, A.R. Structure and Function in Primitive Society. New York: Free Press, 1965.

Robinson, V.M. Humor and the Health Professions. Thorofare, NJ: Slack, 1977.

Sahlins, M.D. On the sociology of primitive exchange. In The Relevance of Models for Social Anthropology, M. Banton (Ed.). London: Tavistock, 1965, pp. 139-236.

Schmidt, H.E., Williams, D.I. The evolution of theories of humour. Journal of Behavioral Science 1: 95-106, 1971.

Singer, P. The Expanding Circle. Ethics and Sociobiology. New York: Farrar, Strauss, and Giroux, 1981.

Strate, J.M. An Evolutionary View of Political Culture. Ph.D. Dissertation, University of Michigan, Ann Arbor, 1982.

Symons, D. The Evolution of Human Sexuality. New York: Oxford University Press, 1979.

Trivers, R.L. The evolution of reciprocal altruism. Quarterly Review of Biology 46: 35-57, 1971.

Van Hooff, J.A.R.A.M. The facial displays of the catarrhine monkeys and apes. In Primate Ethology, D. Morris (Ed.). London: Widenfeld and Nicolson, 1967, pp. 7-67.

- Aspects of the Social Behavior and Communication in Human and Higher Primates. Rotterdam: Bronder-offset, 1971.

- A comparative approach to the phylogeny of laughter and smiling. In Non-Verbal Communication, R.A. Hinde (Ed.). Cambridge: Cambridge University Press, 1972.

Wolff, H.A., Smith, C.E., Murray, H.A. A study of the responses to race-disparagement jokes. Journal of Abnormal and Social Psychology 28: 341-366, 1934.

Yerkes, R.M., Learned, B.W. Chimpanzee Intelligence and its Vocal expressions. Baltimore: Williams and Wilkins, 1925.

Zajonc, R.B. Emotion and facial efference: A theory reclaimed. Science 228: 115-221, 1985. 